\title{
Kemampuan Komunikasi Matematis Mahasiswa melalui Pembelajaran Think Talk Write
}

\author{
Tina Sri Sumartini \\ Program Studi Pendidikan Matematika, Institut Pendidikan Indonesia \\ Jalan Terusan Pahlawan No. 83, Garut, Jawa Barat, Indonesia \\ tina.srisumartini@gmail.com
}

Artikel diterima: 07-05-2019, direvisi: 21-09-2019, diterbitkan: 30-09-2019

\begin{abstract}
Abstrak
Kemampuan komunikasi matematis perlu dimiliki mahasiswa untuk menyelesaikan masalah matematika. Peningkatan kemampuan komunikasi perlu didukung oleh pembelajaran yang tepat, diantaranya pembelajaran Think Talk Write (TTW). Tujuan penelitian ini yaitu menganalisis pencapaian dan peningkatan kemampuan komunikasi mahasiswa antara yang belajar dengan pembelajaran Think Talk Write dan konvensional, serta mengetahui interpretasi peningkatan kemampuan komunikasi mahasiswa dari kedua kelas. Metode penelitian yaitu kuasi eksperimen. Teknik pengambilan sampel dengan teknik Purposive Sampling dengan sampel sebanyak dua kelas di Program studi Pendidikan Matematika Institut Pendidikan Indonesia. Analisis data secara kuantitatif dengan uji gain ternormalisasi dan Mann Whitney. Hasil penelitian yaitu pencapaian dan peningkatan kemampuan komunikasi mahasiswa yang belajar dengan pembelajaran Think Talk Write lebih baik dari mahasiswa yang belajar dengan pembelajaran konvensional, peningkatan kemampuan komunikasi matematis mahasiswa yang belajar dengan pembelajaran Think Talk Write memiliki interpretasi tinggi sedangkan peningkatan kemampuan komunikasi matematis mahasiswa yang belajar dengan pembelajaran konvensional memiliki interpretasi sedang.

Kata Kunci: Kemampuan Komunikasi Matematis, Think Talk Write, kuasi eksperimen
\end{abstract}

\section{Mathematical Communication Ability of Student through Think Talk Write Learning}

\begin{abstract}
Communication ability needs to be possessed by students to solve mathematical problems. Improved communication skills need to be supported by appropriate learning, one of which is learning Think Talk Write (TTW). The purpose of this study is to analyze the achievement and improvement of communication ability between students who are learning with Think Talk Write learning and conventional learning, as well as to find out interpretations of improved communication ability of students from both classes. The research method is quasi-experiment. The sampling technique is the purposive sampling technique by taking a sample of two classes in the Mathematics Education Study Program of the Institut Pendidikan Indonesia. Data analysis was performed quantitatively using the normalized gain test and Mann Whitney. The results of the study are the achievement and improved of communication skills of students who study with Think Talk Write learning is better than students who study with conventional learning, improvement of mathematical communication skills of students who study with Think Talk Write learning has a high interpretation while increasing mathematical communication skills of students who study with conventional learning have medium interpretations.

Keywords: Mathematical Communication Ability, Think Talk Write, quasi-experiment
\end{abstract}




\section{Pendahuluan}

Komunikasi merupakan bagian penting dalam kehidupan sehari-hari. Bentuk komunikasi dapat berupa tulisan dan lisan. Dalam pembelajaran, komunikasi diperlukan oleh mahasiswa sebagai cara menyampaikan pendapat dan memperoleh pengetahuan. Kemampuan dikembangkan dengan pemberian masalah terbuka. Dosen dapat mengembangkan pertumbuhan pengetahuan matematika mahasiswa melalui cara yang mereka minta dan menanggapi pertanyaan (Piccolo, Harbaugh, Carter, Capraro, \& Capraro, 2008).

Kemampuan komunikasi perlu dimiliki mahasiswa untuk meningkatkan pemahaman mahasiswa terhadap kegunaan matematika itu sendiri. Paradigma pembelajaran dewasa ini telah mengalami perubahaan, mahasiswa harus mendominasi aktivitas pembelajaran didalam kelas, mahasiswa sebagai subyek sekaligus objek pembelajaran, dan pengetahuan harus dibangun secara aktif oleh mahasiswa melalui interaksi kelompok.

Komunikasi secara umum merupakan aktivitas interaksi sosial, aktifitas tersebut dapat berupa berbagi ide, selanjutnya melalui komunikasi ide-ide dapat direfleksikan, didiskusikan, diperbaiki, atau mungkin ditolak. Sumarmo (2003) mengatakan kemampuan komunikasi matematis merupakan kemampuan yang dapat menyertakan dan memuat berbagai komunikasi mahasiswa perlu

kesempatan untuk berkomunikasi dalam bentuk: a) Menyatakan suatu situasi, gambar, diagram atau benda nyata ke dalam bahasa symbol, idea atau model matematika untuk belajar matematika; b) Menjelaskan idea, situasi dan relasi matematika secara lisan atau tulisan; c) Mendengarkan, berdiskusi dan menulis tentang matematika; d) Membaca dengan pemahaman suatu representasi matematika tertulis; e) Membuat konjektur, menyusun argumen, merumuskan defenisi dan generalisasi; dan f) Mengungkapkan kembali suatu uraian atau paragraf matematika dalam bahasa sendiri.

Beberapa penelitian sebelumnya yang melihat pentingnya kemampuan komunikasi matematis ini untuk dikaji dan dikaitkan dengan model pembelajaran: 1) Berbasis Penemuan Terbimbing (Rahmi, Yerizon, \& Musdi, 2017); 2) Problem Based Learning (Alamiah \& Afriansyah, 2017); 3) Number Head Together (Lagur, Makur, \& Ramda, 2018); 4) Model Eliciting Activities (Asmara \& Afriansyah, 2018); 4) Group Investigation (Nuraeni, 2018); dan 6). Contextual Teaching and Learning (Dewi \& Afriansyah, 2018)

Dengan demikian, dalam pembelajaran di kelas perlu membiasakan mahasiswa untuk memberikan pendapat tehadap setiap jawabannya serta memberikan tanggapan terhadap orang lain, sehingga apa yang sedang dipelajari menjadi lebih bermakna bagi mahasiswa.

Upaya mengembangkan kemampuan komunikasi perlu disertai pembelajaran

Mosharafa: Jumal Pendidikan Matematika Volume 8, Nomor 3, September 2019 Copyright $\odot 2019$ Mosharafa: Jurnal Pendidikan Matematika 
yang tepat, salah satunya yaitu model pembelajaran Think Talk Write. Pembelajaran Think Talk Write (TTW) dibangun oleh tiga tahap yaitu think, talk, and write (Huinker\&Laughlin ,1996). Think berarti memikirkan sesuatu permasalahan, talk berarti menyampaikan gagasan hasil proses berpikirnya, dan write berarti menuliskan hasil dari proses berpikir. Ketiga rangkaian kegiatan tersebut memberikan peluang kepada mahasiswa untuk aktif dalam pembelajaran matematika.

\section{Think (Berpikir)}

Tahap berpikir ini melibatkan pikiran mahasiswa sendiri dalam memberikan respon terhadap masalah yang diberikan sehingga dapat menimbulkan konflik kognitif. Selama proses pembelajaran, mahasiswa disiapkan untuk selalu berpikir melalui pemberian masalah matematika. Gagasan dalam proses berpikir mahasiswa dapat muncul dari penjelasan dosen, hasil3. pengetahuan sebelumnya, informasi dari temannya, atau buku sumber (Sitorus \& Masrayati, 2016).

Proses berpikir mahasiswa memerlukan waktu, oleh karena itu, dosen perlu mengalokasikan waktu sesuai dengan kemungkinan lamanya proses berpikir mahasiswa. Dosen perlu memikirkan kendala yang mungkin terjadi pada saat pembelajaran (Sullivan, Borcek, Walker, \& Rennie, 2016). Pertimbangan tersebut disesuaikan dengan tahapan berpikir mahasiswa mengenai materi matematika.

Oleh karena itu dosen perlu memperhatikan langkah yang harus digunakan untuk menuntun jawaban ke arah yang benar Tahap Verifikasi yaitu tahap untuk memeriksa gagasan yang telah diperoleh. Pada tahap ini perlu terjalin komunikasi antar mahasiswa dan juga dosen.

\section{Talk (Berbicara)}

Pemahaman akan terbentuk saat seseorang dapat berbicara atau menyampaikannya kepada orang lain (Rivard, L \& Straw, 1999). Mahasiswa yang paham mengenai materi matematika akan teruji kepahamannya jika ia mampu menjelaskan konsep matematika tersebut kepada temannya. Tahap berbicara penting untuk menghasilkan, mengklasifikasi, berbagi, dan mendistribusikan gagasan (Rivard, L \& Straw, 1999). Oleh karena itu, dosen perlu memberikan fasilitas agar mahasiswa dapat saling berbicara sebagai sarana bertukar ide matematika.

\section{Writing (Menulis)}

Menulis memiliki dua peran yang berbeda namun saling melengkapi, yaitu menulis sebagai keterampilan yang menarik tentang penggunaan strategi (seperti merencanakan, mengevaluasi, dan merevisi teks) untuk mencapai berbagai macam tujuan, dan menulis merupakan sarana untuk memperluas dan memperdalam pengetahuan mahasiswa (Graham, S., \& Perin, 2007). Ketika mahasiswa ingin merencanakan konsep pembelajaran matematika, maka ia harus mampu untuk menuliskannya secara terstruktur. Begitu juga ketika mahasiswa ingin mengetahui sejauh mana

\section{Mosharafa: Jurnal Pendidikan Matematika} 379 
pemahamannya mengenai konsep aktivitas pembelajaran, memecahkan matematika, maka perlu melakukan evaluasi dengan menuliskan masalah matematika, menjelaskan ide pemahamannya dalam bentuk tulisan.

Menulis yang baik membantu seseorang untuk bisa berpikir dengan baik tentang matematika dan jika sesorang tidak bisa menjelaskan ide matematika secara bertulis artinya orang tersebut tidak memahami matematika (Houston, 2009). Menulis menjadi bagian dari bentuk komunikasi dalam pembelajaran matematika. Aktivitas menulis akan mampu mengembangkan cara berpikir mahasiswa terhadap matematika dan menulis pun menjadi sarana untuk menyimpan hasil pemikiran matematika. Menulis tidaklah mudah sehingga diperlukan latihan yang terus menerus agar bisa fasih dalam melaksanakannya. Oleh karena itu, pembelajaran hendaklah disertai dengan aktivitas menulis baik yang berkaitan dengan konsep matematika maupun berkaitan dengan aktivitas pembelajaran.

Berdasarkan hal tersebut, menulis dalam pembelajaran matematika perlu dilakukan sebagai sarana pengembangan berpikir matematis mahasiswa. Menulis merupakan aktivitas aspek psikomotorik yang berpengaruh terhadap aspek kognitif mahasiswa. Menulis mendorong tingkat efektifitas kognitif yang memaksimalkan potensi belajar untuk memodifikasi dan merestrukturisasi pengetahuan matematika (Noraini, 2009)

Tugas menulis dalam matematika terdiri dari 4 kategori, yaitu: mencatat 380 matematika, dan menulis tentang proses pembelajaran (Burns, 2004)

a) Menulis catatan pembelajaran pembelajaran

Selama proses pembelajaran, mahasiswa melakukan berbagai macam kegiatan yang harus diingat sebagai tahap dalam pembelajaran. Terkadang mahasiswa lupa terhadap apa yang sudah dialami selama pembelajaran. Oleh karena itu, mahasiswa perlu mencatatnya dalam bentuk catatan pembelajaran. Dalam tahap ini, mahasiswa memiliki cara yang berbeda dalam menuliskan pengalamannya sehingga pola berpikirnya pun akan berbeda.

b) Memecahkan masalah matematika

Dalam menyelesaikan masalah matematika, mahasiswa perlu menuliskan rangkaian proses penyelesaian yang tepat sehingga diperoleh jawaban yang benar. Proses tersebut dapat menyebabkan konflik kognitif sehingga berpikir matematis mahasiswa dapat berkembang.

c) Menjelaskan Ide Matematika

Mahasiswa harus bisa menulis konsep dengan benar sehingga dapat menjelaskan konsep matematika dengan baik sesuai dengan apa yang ia tulis. Proses menjelaskan ide matematika memberikan peluang kepada mahasiswa untuk lebih memahami matematika secara menyeluruh.

d) Menulis tentang proses pembelajaran

Tugas menulis sebagai bagian dalam pembelajaran matematika, bukan hanya Mosharafa: Jumal Pendidikan Matematika Volume 8, Nomor 3, September 2019 Copyright $\odot 2019$ Mosharafa: Jurnal Pendidikan Matematika 
menulis tentang ide matematika melainkan menuliskan proses apa yang telah dilalui mahasiswa selama pembelajaran sehingga dapat menjadi bahan evaluasi untuk pertemuan berikutnya.

Tujuan penelitian ini adalah untuk menganalisis pencapaian dan peningkatan kemampuan komunikasi matematis mahasiswa yang belajar dengan pembelajaran Think Talk Write dengan konvensional serta interpretasi peningkatannya.

\section{Metode}

Metode penelitian ini dilakukan secara kuantitatif untuk mengetahui kemampuan komunikasi matematis mahasiswa. Desain penelitian yang digunakan yaitu desain kuasi eksperimen (The Pretest Posttest Non-Equivalent Group Design) sebagai berikut:

$\begin{array}{lrrr}\text { Eksperimen } & 0 & X & 0 \\ \text { Kontrol } & 0 & 0\end{array}$

(Cohen, Manion, Lecturer, Morrison, \& Lecturer, 2007)

Populasi penelitian ini yaitu mahasiswa jurusan pendidikan matematika di Institut Pendidikan Indonesia Garut. Teknik sampling yang digunakan yaitu purposive sampling dengan mengambil dua kelas yang masing-masing diberikan pembelajaran TTW dan konvensional. Materi yang digunakan dalam penelitian ini yaitu fungsi kuadrat. Di awal dan akhir pembelajaran, kedua kelompok sampel tersebut diberikan tes kemampuan komunikasi matematis tentang materi fungsi kuadrat. Analisis data dilakukan dengan menggunakan uji sttistik.

Hipotesis penelitian ini yaitu:

1. Pencapaian kemampuan komunikasi matematis mahasiswa yang belajar dengan pembelajaran Think Talk Write lebih baik dibandingkan mahasiswa yang belajar dengan pembelajaran konvensional

2. Peningkatan kemampuan komunikasi matematis mahasiswa yang belajar dengan pembelajaran Think Talk Write lebih baik dibandingkan mahasiswa yang belajar dengan pembelajaran konvensional

\section{Hasil dan Pembahasan}

Data deskriptif hasil penelitian dapat dilihat pada tabel 1 berikut.

Berdasarkan tabel 1, diperoleh kesimpulan bahwa rata-rata postes kemampuan komunikasi matematis mahasiswa yang belajar dengan pembelajaran TTW lebih tinggi dari mahasiswa yang belajar dengan pembelajaran konvensional. Begitu juga dengan data $\mathrm{N}$-gain kemampuan komunikasi matematis mahasiswa yang belajar dengan pembelajaran TTW lebih

Tabel 1

Analisis Deskriptif Kemampuan Komunikasi Matematis

\begin{tabular}{cccrc}
\hline & \multicolumn{3}{c}{ Kelas Think Talk } & \multicolumn{2}{c}{ Kelas } \\
& \multicolumn{2}{c}{ Write } & \multicolumn{2}{c}{ Konvensional } \\
\hline & $\bar{x}$ & $\mathrm{~s}$ & $\bar{x}$ & $\mathrm{~s}$ \\
Pretes & 0,18 & 0,55 & 0,18 & 0,38 \\
Postes & 3,30 & 1,16 & 2,25 & 1,13 \\
N-gain & 0,78 & 0,41 & 0,55 & 0,29 \\
\hline
\end{tabular}


tinggi dari mahasiswa yang belajar dengan pembelajaran konvensional. Peningkatan kemampuan komunikasi matematis mahasiswa yang belajar dengan pembelajaran TTW memiliki interpretasi tinggi sedangkan peningkatan kemampuan komunikasi matematis mahasiswa yang belajar dengan pembelajaran konvensional memiliki interpretasi sedang.

Analisis data inferensial dilakukan dengan menggunakan uji normalitas dan uji Mann Whitney untuk data pretes, postes, dan N-gain. Data pretes digunakan untuk melihat kemampuan awal mahasiswa sebelum diberikan pembelajaran. Data postes digunakan untuk menganalisis pencapaian kemampuan komunikasi matematis mahasiswa. Sedangkan data $\mathrm{N}$-gain digunakan untuk menganalisis peningkatan kemampuan komunikasi matematis mahasiswa. Berikut disajikan hasil uji normalitas data pretes pada table 2 berikut.

Berdasarkan tabel 2 diperoleh kesimpulan bahwa data pretes kemampuan komunikasi matematis mahasiswa pada kedua kelas tidak berdistribusi normal dengan taraf nyata 0,05 . Karena kedua tidak kelas berdistribusi normal maka dilanjutkan dengan uji Mann Whitney. Adapun

Tabel 2

Hasil Uji Normalitas Data Pretes

\begin{tabular}{|c|c|c|c|}
\hline Kelas & Statistic & df & Sig. \\
\hline $\begin{array}{l}\text { Think } \\
\text { Write }\end{array}$ & 0,361 & 40 & 0,000 \\
\hline Konvensional & 0,462 & 40 & 0,000 \\
\hline
\end{tabular}

hasilnya disajikan pada tabel 3 berikut.

Berdasarkan Tabel 3 diperoleh nilai sig. > 0,05 maka dapat disimpulkan bahwa Tidak terdapat perbedaan kemampuan awal mahasiswa yang belajar dengan pembelajaran TTW dengan mahasiswa yang belajar dengan konvensional.

Selanjutnya dilakukan analisis inferensial untuk data postes dengan terlebih dahulu melakukan uji normalitas. Adapun hasilnya disajikan pada tabel 4 berikut.

Berdasarkan tabel 4 diperoleh kesimpulan bahwa data postes kemampuan komunikasi matematis mahasiswa pada kedua kelas tidak berdistribusi normal dengan taraf nyata 0,05 . Karena data kedua kelas tidak berdistribusi normal maka dilanjutkan dengan uji Mann Whitney. Adapun hasilnya disajikan pada table 5 berikut.

Tabel 3

Hasil Uji Mann Whitney Data Pretes

\begin{tabular}{cc}
\hline Statistic & Nilai \\
\hline Mann-Whitney U & 763,500 \\
Z & $-0,567$ \\
Asymp. Sig (2-tailed) & 0,571 \\
\hline
\end{tabular}

Tabel 4

Hasil Uji Normalitas Data Postes

\begin{tabular}{llll}
\hline Kelas & Statistic & df & Sig. \\
\hline $\begin{array}{l}\text { Think } \\
\begin{array}{l}\text { Write } \\
\text { Konvensional }\end{array}\end{array}$ & 0,643 & 40 & 0,000 \\
\hline
\end{tabular}

Tabel 5

Hasil Uji Mann Whitney Data Postes

\begin{tabular}{cc}
\hline Statistic & Nilai \\
\hline Mann-Whitney U & 399,500 \\
Z & $-4,071$ \\
Asymp. Sig (1-tailed) & 0,000 \\
\hline
\end{tabular}


Berdasarkan Tabel 5 diperoleh nilai sig. < 0,05 maka dapat disimpulkan bahwa pencapaian kemampuan komunikasi mahasiswa yang belajar dengan pembelajaran TTW lebih baik dari mahasiswa yang belajar dengan pembelajaran konvensional.

Selanjutnya dilakukan analisis inferensial untuk data N-gain dengan terlebih dahulu melakukan uji normalitas. Adapun hasilnya disajikan pada tabel 6 berikut.

Berdasarkan tabel 6 diperoleh kesimpulan bahwa data $\mathrm{N}$-gain kemampuan komunikasi matematis pada kedua kelas tidak berdistribusi normal dengan taraf nyata 0,05. Karena kedua kelas tidak berdistribusi normal maka dilanjutkan dengan uji Mann Whitney. Adapun hasilnya dapat dilihat pada tabel 7.

Berdasarkan Tabel 7, diperoleh kesimpulan bahwa peningkatan kemampuan komunikasi matematis mahasiswa yang belajar dengan pembelajaran Think Talk Write lebih baik dari mahasiswa yang belajar dengan

Tabel 6

Hasil Uji Normalitas Data N-gain

\begin{tabular}{|c|c|c|c|}
\hline Kelas & Statistic & $\mathrm{df}$ & Sig. \\
\hline $\begin{array}{l}\text { Think } \\
\text { Write }\end{array}$ & 0,595 & 40 & 0,000 \\
\hline Konvensional & 0,893 & 40 & 0,001 \\
\hline
\end{tabular}

Tabel 7

Hasil Uji Mann Whitney Data N-gain

\begin{tabular}{cc}
\hline Statistic & Nilai \\
\hline Mann-Whitney U & 418,500 \\
Z & $-3,865$ \\
Asymp. Sig (1-tailed) & 0,000 \\
\hline
\end{tabular}

Mosharafa: Jumal Pendidikan Matematika

Volume 8, Nomor 3, September 2019

Copyright @ 2019 Mosharafa: Jurnal Pendidikan Matematika pembelajaran konvensional.

Kemampuan komunikasi matematika merupakan bagian penting dari kognitif seseorang. Kemampuan ini perlu dimiliki oleh mahasiswa untuk menyelesaikan masalah matematika. Kemampuan komunikasi menjadi modal utama mahasiswa ketika menyampaikan gagasan dalam pembelajaran. Komunikasi menjadi kunci keberhasilan pembelajaran sehingga dosen dan mahasiswa bisa menyatu dalam lingkungan belajar yang ideal (Sumartini, 2017)

Berdasarkan hasil analisis data diperoleh hasil mahasiswa di kedua kelas memiliki kemampuan awal yang sama. Hal ini menunjukkan bahwa mahasiswa di kedua kelas layak untuk diberikan perlakuan yang berbeda.

Hasil postes menunjukkan bahwa pencapaian kemampuan komunikasi mahasiswa yang belajar dengan model pembelajaran TTW lebih baik dari mahasiswa yang belajar dengan pembelajaran konvensional. Selain itu, dari hasil pengolahan data gain diperoleh hasil bahwa peningkatan kemampuan komunikasi mahasiswa yang belajar dengan model pembelajaran Think Talk write lebih baik dari mahasiswa yang belajar dengan pembelajaran konvensional.

Hasil tersebut menunjukkan bahwa model pembelajaran Think Talk Write memberikan efek terhadap pencapaian dan peningkatan kemampuan komunikasi matematis mahasiswa. Hal ini diperkuat dengan hasil interpretasi data $\mathrm{N}$-gain 
bahwa peningkatan kemampuan komunikasi matematis mahasiswa yang belajar dengan pembelajaran Think Talk Write memiliki interpretasi tinggi sedangkan peningkatan kemampuan komunikasi matematis mahasiswa yang belajar dengan pembelajaran konvensional memiliki interpretasi sedang. Husnah dan Surya (2017) mengatakan bahwa model pembelajaran Think Talk Write efektif digunakan dalam pembelajaran untuk meningkatkan kemampuan komunikasi matematis.

Model pembelajaran Think Talk Write terdiri dari tiga aktivitas yaitu berpikir, berbicara, dan Menulis. Pelaksanaan pembelajaran ini dilakukan secara berkelompok sehingga memungkinkan mahasiswa dapat saling bertukar pikiran.

Pada tahap Think, mahasiswa diberikan kesempatan untuk memikirkan masalah matematika sehingga dapat diperoleh solusi penyelesaiannya. Tahap ini memungkinkan mahasiswa untuk saling menjelaskan ide, mendengarkan, dan berdiskusi tentang matematika. Selama berlangsung tahap ini, dosen melakukan bimbingan intensif kepada setiap kelompok sehingga proses diskusi terlaksana secara terarah. Gagasan dalam proses berpikir mahasiswa dapat muncul dari penjelasan dosen, hasil pengetahuan sebelumnya, informasi dari temannya, atau buku sumber (Sitorus \& Masrayati, 2016).

Tahap kedua yaitu Talk dimana perwakilian kelompok mahasiswa mempresentasikan hasil diskusinya. Tahap 384 ini memberikan kesempatan kepada mahasiswa untuk mengungkapkan kembali apa yang telah dipikirkan dan didiskusikan di setiap kelompoknya. Hal ini memungkinkan untuk melakukan diskusi dengan ruang lingkup yang lebih luas. Peran dosen pada tahap ini yaitu mendengarkan terlebih dahulu apa yang dipresentasikan mahasiswa dan melakukan klarifikasi di akhir diskusi. Dosen perlu mendengarkan dengan seksama apa yang dikatakan mahasiswa (Sherin, 2000, hal. 122). Hal ini menunjukkan bahwa ketika dosen menganggap mahasiswa mengatakan hal yang keliru ketika persentasi, dosen perlu mendengarkan terlebih dahulu dan meminta penjelasan terhadap apa yang dikatakan oleh mahasiswa. Dosen harus membantu mahasiswa untuk mengklarifikasi pernyataan mereka dan fokus untuk memberikan kesempatan bagi mahasiswa untuk mendiskusikannya (NCTM, 2000).

Tahap ketiga yaitu write dimana mahasiswa menuliskan kembali pengetahuan yang diperoleh selama tahap think dan talk. Hasil yang diperoleh dari pemikiran dalam kelompok mungkin saja berbeda dengan hasil ketika tahap presentasi. Hal ini akan memungkinkan mahasiswa untuk melakukan refleksi terhadap apa yang telah dipikirkannya sehingga pengetahuan yang diperoleh lebih komprehensif. Menulis merupakan sarana untuk memperluas dan memperdalam pengetahuan mahasiswa (Graham, S., \& Perin, 2007)

Mosharafa: Jumal Pendidikan Matematika Volume 8, Nomor 3, September 2019 Copyright $\odot 2019$ Mosharafa: Jurnal Pendidikan Matematika 
Berdasarkan proses pembelajaran Think Talk Write tersebut, kemampuan komunikasi mahasiswa akan berkembang sehingga dapat meningkatkan prestasinya. Kemampuan komunikasi mahasiswa berkorelasi dengan keberhasilan di perguruan tinggi (Rubin \& Graham, 1988).

\section{Penutup}

Berdasarkan hasil analisis data dan pembahasan, diperoleh kesimpulan yaitu pencapaian kemampuan komunikasi matematis mahasiswa yang belajar dengan pembelajaran Think Talk Write lebih baik dari mahasiswa yang belajar dengan pembelajaran konvensional, peningkatan kemampuan komunikasi matematis mahasiswa yang belajar dengan pembelajaran Think Talk Write lebih baik dari mahasiswa yang belajar dengan pembelajaran konvensional, peningkatan kemampuan komunikasi matematis mahasiswa yang belajar dengan pembelajaran Think Talk Write memiliki interpretasi tinggi sedangkan peningkatan kemampuan komunikasi matematis mahasiswa yang belajar dengan pembelajaran konvensional memiliki interpretasi sedang.

\section{Daftar Pustaka}

Alamiah, U., \& Afriansyah, E. A. (2017). Perbandingan Kemampuan Komunikasi Matematis Siswa antara yang Mendapatkan Model Pembelajaran Problem Based Learning dengan Pendekatan Realistic Mathematics Education dan Open-

\section{Mosharafa: Jurnal Pendidikan Matematika}

Volume 8, Nomor 3, September 2019

Copyright @ 2019 Mosharafa: Jurnal Pendidikan Matematika
Ended. Mosharafa: Jurnal Pendidikan Matematika, 6(2). 207-216. DOI: https://doi.org/10.31980/moshar afa.v6i2.308

Asmara, R., \& Afriansyah, E. A. (2018). Perbedaan Peningkatan Kemampuan Komunikasi Matematis Siswa antara Model Eliciting Activities dan Discovery Learning. Suska Journal of Mathematics Education, 4(2), 78-87.

Burns, M. (2004). Writing in math. Educational Leadership, 62(2), 30-33. https://doi.org/10.9707/2168-

149X.1522.

Cohen, L., Manion, L., Lecturer, P., Morrison, K., \& Lecturer, S. (2007). Research Methods in Education.

Dewi, S. S., \& Afriansyah, E. A. (2018). Kemampuan Komunikasi Matematis Siswa Melalui Pembelajaran CTL. JIPMat, 3(2). 145-155.

Graham, S., \& Perin, D. (2007). Writing next: Effective strategies to improve writing of adolescents in middle and high schools. Washington, DC: Alliance or Excellent Education.

Houston, K. (2009). How to Think Like A Mathematician. New York: Cambridge University Press.

Huinker, D., \& Laughlin, C. (1996). Talk your way into writing. Years book.

Husnah, U., \& Surya, E. (2017). The Effectiveness of Think Talk Write Learning Model in Improving Students' Mathematical Communication skills at MTs Al Jami'yatul Washliyah Tembung. Internasional Journal of Sciences: 
Basic and Applied Research (IJSBAR). 34 (2).

Lagur, D. S., Makur, A. P., \& Ramda, A. H. (2018). Pengaruh Model Pembelajaran Kooperatif Tipe Numbered Head Together (NHT) terhadap Kemampuan Komunikasi Matematis. Mosharafa: Jurnal Pendidikan Matematika, 7(3). 357368.

DOI: https://doi.org/10.31980/moshar afa.v7i3.160

National Council of Teachers of Mathematics. (2000). Principles and standards for school mathematics. Virginia: National Council of Teachers of Mathematics, Inc.

Noraini, I. (2009). Enhancing Students' Understanding in Calculus Trough Writing. International Electronic Jurnal of Mathematics Education, 4.

Nuraeni, R. (2018). Perbandingan Kemampuan Komunikasi Matematis Mahasiswa antara yang Mendapatkan Pembelajaran Group Investigation Dengan Konvensional pada Mata Kuliah Kalkulus Integral. Mosharafa: Jurnal Pendidikan Matematika, 7(2). 219-228.

DOI: https://doi.org/10.31980/moshar afa.v7i2.29

Piccolo, D. L., Harbaugh, A. P., Carter, T. A., Capraro, M. M., \& Capraro, R. M. (2008). Quality of Instruction: Examining Discourse in Middle School Mathematics Instruction. Journal of Advanced Academics, 19(3), 376-410. Rahmi, M., Yerizon, Y., \& Muhdi, E. (2017). 386

$\begin{array}{ll}\text { Tahap Preliminary } & \begin{array}{l}\text { Research } \\ \text { Perangkat }\end{array} \\ \text { Pengembangan } & \begin{array}{l}\text { Pembelajaran Berbasis } \\ \text { Penemuan }\end{array}\end{array}$

Terbimbing untuk Meningkatkan

Kemampuan Komunikasi Matematis Peserta Didik Kelas VIII Mts/SMP. Mosharafa: Jurnal Pendidikan Matematika, 6(2). 237-246. DOI: https://doi.org/10.31980/moshar afa.v6i2.311

Rivard, L \& Straw, S. B. (1999). The Effect of Talk and Writing on Learning Science: An Exploratory Study, 566593.

Rubin, R. B., \& Graham, E. E. (1988). Communication correlates of college success: An exploratory investigation. Communication Education, 37(1), 1427.

https://doi.org/10.1080/0363452880 9378700

Sherin, M. G. (2000). Facilitating Meaningful Discussion of Mathematics. Mathematics Teaching in the Middle School, 6(2), 122-125.

Sitorus, J., \& Masrayati. (2016). Students, creative thinking process stages: Implementation of realistic mathematics education. Thinking Skills and Creativity, 22, 111-120. https://doi.org/10.1016/j.tsc.2016.09. 007

Sullivan, P., Borcek, C., Walker, N., \& Rennie, M. (2016). Exploring a structure for mathematics lessons that initiate learning by activating cognition on challenging tasks. Journal of Mathematical Behavior, 41, 159Mosharafa: Jurnal Pendidikan Matematika Volume 8, Nomor 3, September 2019 Copyright $\odot 2019$ Mosharafa: Jurnal Pendidikan Matematika 
170.

https://doi.org/10.1016/j.jmathb.201

5.12 .002

Sumarmo, U. (2003). Pembelajaran Keterampilan Membaca Matematika. Makalah pada Pelatihan Nasional TOT Guru Matematika dan Bahasa Indonesia SLTP di Bandung.

Sumartini, T. S. (2017). Meningkatkan Kemampuan Komunikasi Matematis Siswa Melaui Model Pembelajaran Predict Observe Explanation. JES-MAT, 3(2), 167-176

\section{Riwayat HidUP PENULIS}

\section{Dr. Tina Sri Sumartini, M.Pd.}

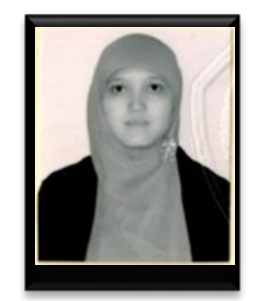

Lahir di Garut, 11 Maret 1988. Staf pengajar di Institut Pendidikan Indonesia. Studi S1 Pendidikan Matematika STKIP Garut, lulus tahun 2010; S2 Pendidikan matematika Universitas Pendidikan Indonesia, Bandung, lulus tahun 2014; dan S3 Pendidikan matematika Universitas Pendidikan Indonesia, Bandung, lulus tahun 2019. 
